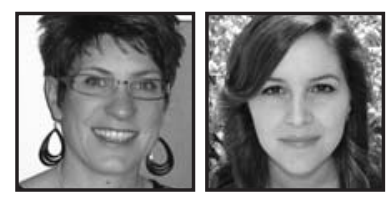

\title{
Teaching for Change: Teacher Candidates' Anti-Oppression Elementary School Lesson Plans
}

\author{
Christine L. Cho, Schulich School of Education \\ Shannon Tersigni
}

\section{ABSTRACT}

This paper explores pre-service elementary teacher candidates' written reflections on an assignment for a mandatory Bachelor of Education course in Ontario, Canada. The assignment required the teacher candidates (TCs) to create and teach one 40-minute anti-oppression lesson (racism, sexism, homophobia, etc.) in a public elementary school with students in senior kindergarten to grade 6 . Two key themes are discussed in the paper: first, the ways in which TCs found convenient excuses as to why they were unable to fully engage with a topic; and, second, the fears identified by the TCs in terms of teaching sensitive issues.

These children in their own special way taught me that they were not too young, and that no matter the age, topic areas such as homophobia SHOULD be discussed in the classroom without discomfort on anyone's part. - Matilda

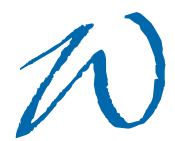

hile Canada is championed for being a "cultural mosaic," those in the process of becoming teachers, teacher candidates (TCs), certainly in Ontario, most commonly identify as White, female, heterosexual, middle class, Canadian-born with English as their first language. TCs often express a lack of experience with critical discussions about race, gender, sexuality, and nationality, among other socio-cultural topics. This paper draws from a project completed in an initial teacher education program in Ontario, Canada in 2012. The project drew from an assignment in a mandatory socio-cultural course which required elementary (Primary/ Junior) $\mathrm{TCs}^{2}$ to work together to create and deliver an anti-oppression lesson with 
elementary students using racism, sexism, homophobia, ableism, or classism as the underlying theme. This project centralizes TCs' reflections as a method of interrogating experiences with inclusion and socially just perspectives. What follows is an analysis of TCs' reflections on the experience.

\section{Taking a Risk: Deepening an Understanding of Inclusion}

As Sleeter and Owuor (2011) premise,

[a] majority of teacher education candidates in the United States come from White, female, heterosexual, middle-class backgrounds, which are increasingly at odds with the backgrounds of students. Although all prospective teachers need preparation to teach diverse students well, the discrepancy between the backgrounds of the majority of pre-service teachers and realities of public schools creates challenges to teacher education programs. (p. 534)

In the initial teacher education program that is the focus of this project, the Canadian demographics are in keeping with Sleeter and Owuor's findings. In 2006, 16.2\% of Canadians were visible minorities with only $6.9 \%$ of the teaching force visible minorities (Ryan, Pollock, \& Antonelli, 2009). While greater diversity in the elementary and secondary student population is evident in some of the larger urban centres and increasingly in the smaller cities and rural areas in which the TCs complete their fieldwork, for the most part, the participants in this project complete their fieldwork in predominantly White settings.

A common presumption expressed by the TCs is that engaging elementary students in anti-oppression work is unnecessary, perhaps "risky," particularly in predominantly White classrooms. Responses from former TCs suggest that anti-oppression work is theoretically sound but not practical or possible to implement in an elementary classroom. Fear of upsetting parents and students is the most often cited explanation for avoiding or restricting anti-oppression work in the classroom. By partnering with a local elementary school and engaging in a project that requires TCs to teach antioppression lessons to elementary students, TCs are also being asked to: examine how they are implicated in the reproduction of the status quo; explore the ways in which the power of the dominant group is maintained; and confront their fears. 


\section{Questions That Framed the Project}

As Nieto (2003) argues, students from the dominant culture need "multicultural education" more so than those from minority groups because they are generally the most miseducated or uneducated about diversity. Lewis (2001) argues, "race matters as much in (almost) all-White settings ... as it does in any multiracial inner city schoolperhaps even more so" (p. 804). From this landscape, we draw from Milner's (2003) assertion that TCs need opportunities to develop instructional methods and tools that allow them to pose tough questions about issues of race (and we include other aspects of social location, namely: socio-economic class, sexual orientation, gender, nationality, ability, age, etc.).

This project was premised on engaging TCs with critical multiculturalism (James, 2005; May, 1999; McLaren, 1995) and, as such, asks the following four questions: first, in what ways are TCs prepared to implement an anti-oppression framework? Second, what are the barriers to implementing anti-oppression work in the classroom? Third, as future educators, will the TCs use their locations as insiders/outsiders to make transparent the barriers that exist in schools? Fourth, will they continue to reproduce the status quo? It is through an assignment designed to specifically press TCs to design and teach an anti-oppression lesson that we delve into the questions that framed this research.

\section{The Assignment: Teaching With Change in Mind}

The socio-cultural course is offered during a time when TCs are not on placement in schools, so it can be challenging to make direct and timely theory-practice linkages. The "Teaching With Change in Mind" assignment required the cooperation of an elementary school close enough to the university so the TCs could teach their lesson and return to their classes. In 2011/12 there were 90 TCs enrolled in the course and the partner school provided five classrooms and three days in January 2012 for the lessons which included: an SK-grade 1; grade 2, grade 3/4; grade 4/5 and a grade 5/6 class. The TCs were encouraged to work in groups of five to six. The assignment required TCs to include concrete and specific connections to the Ontario Ministry of Education's policy document, Realizing the Promise of Diversity: Ontario's Equity and Inclusive Education Strategy (2009), and to carefully consider the grade and subject-specific expectations when designing a 40-minute anti-oppression lesson plan.

At the university the TCs were required to share their lesson plan ideas during an in-class workshop in order to elicit peer and instructor feedback and critique. Next, the plans were formalized and submitted to the instructor who then forwarded them to the host classroom teachers. The host classroom teachers had one month to give 
any feedback or raise any concerns (none were raised). Finally, the lessons were taught. Afterwards, the TCs were asked to:

- reflect upon and explore an issue that intrigued them;

- consider areas that made them question their work or doubt what they understood about teaching; and,

- explore what they want to learn more about specifically related to the objectives of the course: social location and human development.

\section{Unpacking the Reflections: Data Collection and Analysis}

The TCs' self-reflections are the primary source of data for this project. Tri-council ethics approval was obtained to collect and analyze the TCs' reflections written after the delivery of the anti-oppressive lesson plans. As the course instructor was also the researcher, to ensure confidentiality and anonymity, a marker-grader was hired to assess the reflections. The TCs enrolled in the socio-cultural course were asked to voluntarily share their reflections after the assignment had been assessed and returned to the students. TCs who gave informed consent to participate in the project submitted their reflections to a research assistant who removed direct identifiers from the assignments to protect the identity of the participants. The participants were assigned a parallel cultural pseudonym and the reflections were coded to reflect the participants' workshop topic and the grade level. Of the almost 90 candidates enrolled in the course, 39 participated in the research project (six males and 33 females). Of the 33 females, six self-identified as visible minorities and one female participant self-identified as Aboriginal. All six males self-identified as White. The average age of the students enrolled full-time in the program was 26.86 with a median age of 24 . The youngest student was 21 years of age and the oldest was 47 years of age.

Analysis of the data included process coding. The codes reflect the common and various themes that were identified from the data. The data was analyzed using what Tesch (1990) describes as "de-contextualization" to "separate relevant portions of data from their context" (p. 118) in order to identify themes and coding categories and "re-contextualization" or the reassembling of the data to create "pools of meanings" (p. 122) to present a unified and coherent picture. The data was triangulated for reoccurring themes among the participants using the techniques described by Bogdan and Biklen (1998). 
Before embarking on a discussion of the findings, the learning environment will be described including some of the issues and challenges that occurred at the beginning of the process.

\section{Preparing the Lessons: Challenges}

There were many challenges in terms of the TCs choosing their grade and topic. It was interesting to observe the ways in which some TCs worked to avoid so-called "sensitive topics" (racism and homophobia) as well as the ways in which the same topics (racism and homophobia) were fought over. Overwhelmingly, most TCs wanted either the grade 4/5 class or the grade 6 class and many had to be encouraged to choose the younger grades. None of the groups chose classism as a topic.

Another challenge was working with the TCs to see how issues could be embedded within the lesson. It was very challenging for some TCs to envision a lesson that was not a lecture on the issue but rather presenting a lesson that disrupted the takenfor-granted in schools and within individuals; lessons that taught a math concept, for example, but perhaps exposed classism. Ultimately, most groups opted to connect their lessons with social studies, language arts (media literacy), and/or physical and health education curriculum expectations as a way to legitimize lessons that overtly addressed their particular "ism."

\section{Findings}

As we examined the TCs' reflections, several themes were identified. For the purposes of this paper, we will elaborate on two key themes: first, the ways in which TCs found "convenient" reasons or excuses to rationalize their level of engagement with the topic(s); and second, the ways in which fear was a debilitating factor.

Convenient excuses. Examining privilege and exposing structural inequities is uncomfortable work at best. As Briskin (1998) argues, "Naming the practices of power can be very unsettling for those who benefit from them, and even for those who do not benefit but have developed a comfortable acceptance of and familiarity with them" (p. 27). Compounding critical discussions around identity is the tendency for neophyte teachers to focus on their experiences rather than shifting the focus to the experiences of the students (Anderson \& Stillman, 2010). As such, it was difficult for the TCs to see the larger picture, a positionality that is revealed in the data. For example, one prominent theme that may also be attributed to the position of teacher-as-student is navigating 
aspects of teaching that were deemed by the TCs to be out of their control, which became reasons to justify not engaging in-depth with the subject matter. These included: first, unfamiliarity with the classroom and not knowing the students in advance or what we have termed "teaching to the 'unknown' "; and, second, underestimating the elementary students' background knowledge and ability to engage with the material. While these might be common concerns for any $\mathrm{TC}$, the concerns were possibly heightened by the TCs' discomfort with the subject matter. Aspects deemed to be out of the TCs' control were sometimes used to justify and explain why the participants were unable to fully engage with a topic. These two subcategories of convenient excuses will now be discussed in greater detail.

Teaching to the "unknown". In the TCs' reflections several participants expressed concerns about not knowing the elementary students in advance. It would have been preferable for the TCs to meet and interact with the students and the teacher in advance, perhaps on more than one occasion, but the assignment was created to work within the existing parameters of the overall program. Statements such as, "I was not aware of the dynamics of the classroom and the developmental level of the children which created some initial discomfort" [Marianne, Sexism, SK/1] or "I felt uncomfortable planning for a class I had never met before" [Niki, Genderism, 3/4] were common. Sometimes the reflections were indicative of the TCs' lack of experience with the children: "Not knowing the students was a bit difficult at times, as there was no way to predict or anticipate what they might say" [Susan, Genderism, 2].

While this assignment was designed to explore issues of social location, it was also designed to give real-time experience with children at various developmental stages, which required anticipating how students at various ages and stages might respond to different issues, and to take into consideration what would be developmentally appropriate to discuss, and how to structure those conversations and activities. However, the suggestion that greater comfort or established rapport with the children might have increased the depth of discussion is an important point, well articulated by Sienna who writes, "The students would have felt more comfortable with us if they had been able to spend more time getting to know us and realizing that they will not be judged by their opinions and contributions" [Racism, 6].

Finding ways to have the TCs meet and interact with the students in advance would be a desirable future addition to the assignment and the course. Some participants indicated they were not certain about the demographics of the students in advance of their lessons, which caused them some concern. For example, Sheila commented that 
she, "Did not want the workshop to be in a class where there was only one student who was 'African-American'; I did not want them to be singled out" [Racism, 6]. In addition, Heleen wrote, "Overall, I was quite comfortable presenting, but this may have changed if I was presenting to a larger, more diverse group" [Racism, 2].

The comments reveal both a consciousness to be protective of students who might be in the minority and also a fear of engaging in a discussion about racism in the presence of individuals who might have actually experienced it, as in Heleen's response. The TCs' comments are reflective of Milner's (2010) assertion, "if I acknowledge the racial or ethnic background of my students or myself, then I may be considered racist" (p. 121). Rather than viewing the students as individuals who might benefit from a conversation about "Othering" and recognizing the need to explicitly identify and acknowledge racial and ethnic backgrounds, there is a perception that the discussion should be minimized in the presence of visible minority students. Recognizing that race matters and impacts the daily lives of those positioned as "Other" is a difficult shift to make for those TCs who have benefited from and not examined their privileged racial position. The impression that overtly addressing race will be controversial combined with a desire to avoid and deflect controversy, runs the risk of keeping whiteness at the center of the lessons (Thompson, 2003). Next, we will explore the second subcategory of convenient excuses, underestimating the knowledge base of the students.

Underestimating the understanding of elementary students. Perhaps predictably, several of the participants wrote specifically about how much they underestimated what the students would know. As Susan commented, "One of the first things I realized during the presentation was that these kids (and kids in general I'm sure) had much more knowledge than I expected them to have" [Genderism, 3/4].

Mila wrote, "I believe the workshop showed me that students are never too young to explore delicate issues, and have the ability to provide quite candid insight" [Sexism, SK/1]. As well, Sally commented, "This workshop has given me the opportunity to see how students, even at a young age, are aware and interested in topics that are usually swept under the rug" [Genderism, 2].

The opportunity to present lessons on topics classroom teachers might determine to be too sensitive for young students has the potential to both disrupt seasoned teachers' thinking as well as demonstrate to new teachers the capabilities and experiences of the young learners in the classroom, as revealed in this comment by John, 
I found it troubling at times to see how deeply rooted in negativity these second grade students already were... I learned that children are often deeply embedded in their social locations and upbringings and therefore, even at the tender age of 7 and 8 , may already have strong opinions and beliefs on topics such as homosexuality. [Homophobia, 2]

Resistance to anti-oppression work in schools can impede neophyte and aspiring teachers' development of critical multicultural skills and sensitivity and, subsequently, their willingness to participate in equity and culturally relevant education practices (Brown, 2004). Many TCs have a preconceived notion that education is somehow "neutral" and that controversial topics or issues should be ignored or downplayed, a conception that is not disrupted, but rather reinforced by classroom teachers who remark that they do not want to incite parents and wish for harmony as opposed to discord. The TCs' reflections reveal unexamined assumptions held by some classroom teachers regarding what children should know. In this way, classroom teachers may be acting as gatekeepers, operating on the assumption that the students in their classes, the students' families, and/or their friends have not experienced, participated in, or been exposed to larger societal issues such as sexism, racism, classism, ableism, and heterosexism, reinforcing a faulty assumption that learning and classrooms are neutral spaces.

In the next section we will explore the second key theme: the ways in which fear undermined the implementation of the lesson plans.

\section{Fears}

"The lesson wasn't necessarily playing it safe but it also wasn't pushing the envelope." [Macy]

This next section will delve into ways in which many TCs described the preparation and implementation of the anti-oppression lessons as an uncomfortable experience that mobilized some and debilitated others. Several TCs expressed uncertainty in terms of how much "depth" was appropriate for their topic and the grade level, which was one of the tasks of the assignment: making specific and concrete linkages to child development. The comments by Conan reveal the multiple concerns and issues that were confronted by some participants. He writes,

When I first looked at the grades and topics I wanted an older grade, assuming the students would be able to cope with the concepts more easily. I also wanted the 
least touchiest topic from a social political angle. I was extremely worried about backlash from students or parents that would not agree with the lesson approach we take. I was also worried that being a White male and discussing these topics also would open me up to criticism. [Conan, Racism, SK/1]

Conan's reflection reveals the multitude of issues that were of concern: the age of the students, desensitizing the topic, and fear of parental backlash. In addition, Conan's own positionality as a White male with privilege was an area of concern for him. The quote exemplifies themes found in the data, which we will now explore under three subcategories. First, many participants experienced difficulty finding the "right" language that was age appropriate, not contentious, and at the same time professional. Second, some TCs expressed anxiety regarding what they deemed "uncomfortable areas" for discussion and expressed fear in terms of upsetting students, parents, teachers, and even their own colleagues and, as such, participants made conscious decisions to "soften" their topic. Third, in some cases, the TCs' own positionality (as a male, as a White teacher, etc.) made them more conscious of their language and word choices and may have impeded or deepened their connection with the topics and lessons. We begin with a discussion regarding language and terminology.

Finding the "right" language. Many of the TCs described discomfort with using particular terms, such as: racism, sexism, and homosexuality. As Leah commented, "I didn't feel comfortable introducing such controversial words to children, especially if they have never heard them before" [Homophobia, 3/4].

Recognizing their role as "guests" in the host classroom and their location as "student teachers," those who reflected on this aspect of discomfort also tended to provide the classroom teacher with the final decision of whether to use a term or not as evidenced in this reflection, "We asked the teacher if we could use the word sexism in our lesson. She explained to us that she found it unnecessary to say and a little inappropriate so just explain it without the word" [Marianne, Sexism, SK/1].

It is interesting that the TCs asked the host teacher permission to use the term sexism, suggesting they were uncomfortable and possibly wanted a reason not to use the terminology in the lesson. While some TCs describe the response of many host classroom teachers as "cautious," their reflections also reveal that they requested permission on the day the lesson was taught and were denied. The host teachers were provided with the lesson plans in advance so they could raise any concerns. The instructor was not contacted by any of the host teachers before or after the lesson plans were taught. 
In the end, many TCs avoided language that might be contentious or avoided specific vocabulary with the students. The TCs' accounts suggest that some seasoned teachers were uncomfortable with anti-oppression language and the potential impact and possible negative reaction to the words by students and parents: "[The classroom teacher] mentioned to me that the students had NEVER heard that term [sexism] before and would rather us not say it directly for fear of parental phone calls the next day" [Nicola, Sexism, SK/1].

And yet, as Marianne wrote, "As a teacher candidate I was very shocked with the intellectual comments and use of adult awareness that the children used involving sexism. [Sexism, SK/1]. Marianne's reflection reveals a disconnect between the classroom teacher's perception of the students' understanding and their actual capabilities as well as a fear of overtly naming or labelling oppression.

Not only was it found that teachers were uncomfortable with certain words used in their classrooms, but some classroom teachers were also anxious about the lessons: "One piece of knowledge that really made me stop in my tracks was a comment that the classroom teacher made, she mentioned that she was very worried about the presentation and hoped that everything would go 'smoothly' " [Nicola, Sexism, SK/1].

The desire for the lesson to go smoothly seems to be equated with a "successful" lesson with the exception of this reflection, "I am a little ashamed to say that I was hoping at least one homophobic student would blurt out 'faggot' just to get the ball rolling, no matter how disruptive" [Jansen, Homophobia, 3/4]. The majority of participants expressed a desire for the topics to be taught without controversy. Some even expressed overt fear that saying the wrong thing could result in expulsion from the B.Ed program:

I was worried... if we were to discuss a topic or say something that is misinterpreted as racist or politically incorrect we could get kicked out of the program. So going into this project I was extremely nervous and uncomfortable...I had a tremendous amount of fear because we did not get an older grade and we got a very controversial topic. [Conan, Racism, SK/1]

Conan's response indicates the blurring of boundaries between being a university student who is encouraged to delve into difficult subject matter and perceived constraints by governing bodies such as the Ontario College of Teachers, which might result in disciplinary measures for "conduct unbecoming of a teacher." Discussing race and being racist are crucial issues that need to be unpacked at an early point not only 
in teacher education programs, but also throughout students' educational careers. Conan's response is reflective of Milner's (2010) second assertion regarding colourblindness that,

If I admit that people experience the world differently and that race is an important dimension of people's experiences, I may be seen as "politically incorrect." I may offend others in the teacher education classroom discourse if I express my beliefs and reservations about race. (p.21)

When TCs and teachers constrain, censor, and silence themselves, so-called sensitive topics are rarely discussed in classrooms, leaving additional generations without the language and knowledge of oppressive acts and actions. Conan's comment that a statement might be "misinterpreted" as racist negates the oppression by omission that occurs in schools on a daily basis. The assignment specifically required the students to make reference and connection to the Ministry Equity policy document (Ontario Ministry of Education, 2009) as well as the Canadian Charter of Rights and Freedoms in a proactive attempt to disrupt some of the anticipated fears. Integrating the Ministry document was a tactic included to give TCs "permission" to engage in difficult discussions with students, a tactic that was not always successful (quite possibly because of the vagueness of language used within the Equity document itself) as evidenced by Conan's reflection above as well as Nicola and Marianne's request to the host teacher for permission to use the term sexism.

Conan's response also illuminates another fear common to TCs: the trepidation of being monitored or surveilled by the classroom teacher as Macy describes:

The main reason for my discomfort was actually because the classroom teacher was present during our presentation... I feel as though lessons are always more nervewracking when the classroom teacher is present, as they are the ones who can truly judge the material you are presenting. [Homophobia, 4/5]

At one point during Macy's group presentation, the following situation occurred,

A girl ... asked us, "If a boy and boy are married, they can't have a child, they can only adopt one, but what if a girl and a girl get married? Can they have a baby?" I felt so uncomfortable during this question because I was worried about how [the classroom teacher] might take our response, she is the classroom teacher after all and we were simply guests. [Homophobia, 4/5] 
The TCs, as students, are perpetually being marked and graded on the work they do (even though the TCs were not evaluated on the teaching of the anti-oppression lessons) and feel they are being "judged" in this case by the classroom teacher who is viewed as an "expert." As a result, TCs who should be in a unique position to take greater risks instead play it safe for fear of offending anyone. As Nicola asked, "Will the teacher be upset if she doesn't agree with our definition and/or centers?" [Sexism, SK/1].

While TCs felt limited in some ways in terms of their positions as "students" and "guests," their positionality also has the potential to produce an environment for taking greater risks, if, and when, the conditions are optimal. It is an interesting juxtaposition: on the one hand the classroom teachers are viewed as "expert" and yet, on the other hand, anti-oppression lessons and discussions are not common place in most elementary classrooms, hence the impetus for this course assignment.

Many TCs indicated during class discussions that they did not have anti-oppression learning in elementary, secondary school, or even university, leaving them at a loss as to how to begin conversations without knowledge as to what could be deemed "appropriate" language as evidenced by this reflection,

Being in a grade six classroom I felt unaware of the boundaries surrounding racismassociated terminology. Should I be using words like slavery, murder, bombings, hangings, or Ku Klux Klan? Or should I skip the graphic details of our North American history and begin with the fight for equality, teaching about the Underground Railroad, Martin Luther King, and Rosa Parks? [Lacy, Racism, 6]

The TC's concern reveals a dichotomous understanding of racism as viewed through an American perspective, revealing gaps in a Canadian contextual understanding of oppression as well as gaps in terms of deeper understandings of systemic racism and contemporary issues. This understanding of racism may in fact be indicative of two of Milner's (2010) assertions regarding colour blindness, namely, that exploring race as an important dimension of people's experiences may offend others and secondly, the erroneous assertion that racism has ended. As Lewis (2001) has also documented, there seems to be both a refusal and a lack of knowledge in terms of the TCs' ability to discuss so-called "sensitive" issues with mostly White children. Also evidenced in Lacy's reflection is a suggestion that there is a positive and negative way to address racism, which leads into our next subcategory of fear, the ways in which TCs worked to soften their topics. 
Softening the topics. A recurring theme described by many TCs was a position that their lesson was safe from any real controversy, and therefore an easy way to address the topic. Some participants suggested they purposely chose a topic they felt was "less controversial," such as ableism, or altered their topics to "social bullying" or "positive friendships." As Stacie noted, "We chose a topic that was very easy to discuss and left a lot of room for interpretation" [Positive Friendships, SK/1].

Stacie went on to comment that she "still feels conflicted about introducing very young children to the horrors of oppression." It is interesting to note the language used by the participants to discuss oppression, such as "horrors," which gives insight into their rationale for softening the topic. In addition, the presumption that the TC can somehow protect students from the "horrors" of oppression suggests that the TC does not expect very young children would have experienced any form of oppression. Language that illuminates participants' perceptions can also be detected in this excerpt: "As I reflect on the experience of teaching in the anti-oppression workshop, I realize that I stayed within my comfort zone throughout the lesson by not approaching the ugly side, or the depth of racism" [Charles, Racism, SK-1].

Charles' comments about the "ugly side" of racism suggests there exists a corollary "beautiful" or "pretty" side of racism and therefore there must be a "nice" way to present the information or have a discussion. Again, the idea of protecting children from something "ugly" is a motivating factor to rationalize not teaching about difficult subject matter. Fear of discomfort motivates TCs to "play it safe," as opposed to being seen as a necessary element for overcoming challenges and preconceptions. As Lewis (2001) argues, struggle may be the necessary element for change to occur.

TCs also noted greater impact may have occurred if the TCs had gone into more depth. As Charles comments,

I think that fact that we were teaching for a SK/Grade 1 class was an easy excuse to treat the subject in an easy and uncomplicated way ... I think that I was simply more comfortable approaching the issue by having a positive message that we should treat people the same regardless of skin colour. [Charles, Racism, SK-1]

Assuming that discussions about race might be "uncomplicated," compounded with the statement that we should "treat people the same," is evidence of a colour-blind stance (Lewis, 2001; Banks \& Banks, 2007; Milner, 2010) that serves to undermine and dismiss the experiences of racialized individuals who are not "all treated the same" and reinforces the privileged position of White people in our society. 
As Kose and Lim (2010) suggest, perhaps the TCs recognized the "easier" or "softer" introduction to the topic was at the cost of the educational value for the students. In contrast, Sarah, whose group opted to soften their topic to "positive friendships," wrote the following after her experience,

I learned that there are no concrete answers that will guarantee that you will not offend the children or their parents. However, there are ways of teaching respect and opening a dialogue that encourages children to feel they can talk openly. [Positive Friendships, SK/1]

In Sarah's reflection there appears to be a shift from a focus on herself to a focus on the learners and the larger community and the ways in which dialogue can be created, not shut down. Next, we will explore the third subcategory of fear, the participants' own positionality and the ways in which the TCs' social location may have impeded the teaching of their lesson plans.

Participants' positionality. Only a few TCs described their initial discomfort with the lesson plans in terms of their own social location, offering deep insights and revealing their own lack of anti-oppression education or their lack of experience as recipients of oppression, as revealed in this statement: "I suppose I felt a degree of discomfort during the preparation of the lesson, because as a Caucasian, I didn't know how to appropriately address the topic of racism" [Maggie, Racism, 6].

As Milner (2010) argues, in order for new teachers to better understand their positionality in classrooms, they need to build cultural competence. The participants' connection to the coursework and readings also percolated through their reflections, as Maggie continues to elaborate upon with regard to her positionality as a White woman. She states, "[Being White] also hindered my comfort because I thought about some of the "White privileges" I shared with Mclntosh [referring to McIntosh (1990) article read in class], and I began to wonder if I was a suitable presenter for the topic."

Engaging in discussions about race from a privileged position requires an examination of how one is implicated in the current conditions and moving beyond constructions of guilt to a position of action and a dialogue.

\section{Gaps}

There were some noticeable gaps in the participants' reflections. Part of the goal of the course and the assignment was to press the development of the TCs to be critical pedagogues. We anticipated some critical reflection on the curriculum documents 
or a discussion of the ways in which the diversity policy might be used to greater effect, which did not occur. In some ways, we felt the TCs' reflections lacked a critical interrogation of the experience; the TCs were completing an assignment to meet the course requirements and in doing so continued to play it safe in their responses. As well, while TCs mentioned race and their positionality as White TCs, those who were visible minorities did not mention this in their reflections. As well, sexual orientation and religious beliefs were not mentioned or commented upon by any of the participants in their reflections. The only exception concerned TCs enrolled in the course who indicated they would be seeking jobs within the Catholic school board after graduation. Several of these students actively sought to teach a lesson on homophobia as they determined this might be the only opportunity they would have to engage in this type of discussion with elementary students.

We believe assignments such as "Teaching With Change in Mind" are crucial to the development of future teachers because they provide TCs the opportunity to practice anti-oppression teaching with guidance and support. Assignments like this allow TCs to challenge and examine educational structures that may impede the learning of students (Sleeter \& Owuor, 2011).

\section{Conclusion and Future Directions}

We are very cognizant that one 40-minute anti-oppression lesson in an elementary school is not enough to build capacity, but it is a start to deepening future teachers' understanding of inclusion. Having the experience of implementing the lessons with input from multiple stakeholders is one step towards building confidence. In addition, TCs posted their lessons on the university intranet to be shared amongst each other, giving all TCs access to 14 additional anti-oppression lesson plans for their future use in schools.

Through this research it was apparent that the TCs were developing the competence to consider anti-oppression topics in their work. One of the barriers to implementing anti-oppression work in the classroom is a lack of knowledge which we hope the in-school workshops and the collection of lesson plans will provide. Another barrier, lack of confidence, seems to be countered by the collaborative approach.

We would hope that sharing the findings of this project with future TCs may serve to address issues and concerns earlier. Reading the voices of those who have experienced 
teaching anti-oppression lessons and hearing about common fears and issues may press TCs' thinking and further develop TCs' proficiency as culturally responsive pedagogues.

In terms of this project, we envision further framing and refining the assignment to build TCs' cultural competence and to further develop TCs' connection with their own social location and awareness of their students' social locations in schools. Of key importance is recognizing that all students (TCs and elementary pupils) have multiple layers of identity. We would want to create a greater culture of collaboration. The collaborative aspect of this assignment was key to its success and is crucial to future teachers seeing teaching as a communal, multidirectional affair.

\section{Notes}

1. "Matilda" was a teacher candidate in the grade $3 / 4$ class that did a lesson on homophobia. All participant names are pseudonyms.

2. Students enrolled in an initial teacher education preparation program in Ontario, Canada which leads to a Bachelor of Education and certification to teach in two divisions, from Kindergarten to Grade 6 in Ontario schools.

\section{References}

Anderson, L., \& Stillman, J. (2010). Opportunities to teach and learn in high-needs schools: Student teachers' experiences in urban placements. Urban Education, 45(2), 109-141.

Banks, J. A., \& Banks, C. A. (Eds.). (2007). Multicultural education: Issues and perspectives (6th ed.). Hoboken, NY: John Wiley \& Sons, Inc.

Bogdan, R., \& Biklen, S. (1998). Qualitative research for education: An introduction to theory and methods (3rd ed.). Toronto, ON: Allyn \& Bacon.

Briskin, L. (1988). "Negotiating power in the classroom: The example of group work." Canadian Women's Studies 17, no. 4: 23-28.
Brown, D.F. (2004). Urban teachers' professed classroom management strategies: Reflections of culturally responsive teaching. Urban Education, 39, 3, 266-289.

James, C. (2005). Introduction: Perspectives on multiculturalism. In C. E. James (Ed.), Possibilities and limitations: Multicultural policies and programs in Canada (pp. 12-20). Halifax, NS: Fernwood Publishing.

Kose, B. W., \& Lim, E. (2010). Transformative professional learning within schools: Relationship to teachers' beliefs, expertise and teaching. The Urban Review, 43, 196-216. 
Lewis, A. (2001). There is no "race" in the schoolyard: Colorblind ideology in an (almost) all White school. American Educational Research Journal, 38(4), 781-811.

May, S. (Ed.). (1999). Critical multiculturalism: Rethinking multicultural and antiracist education. Levittown, PA: Falmer Press.

Mclntosh, P. (1990). White privilege: Unpacking the invisible knapsack. Independent School, Winter, 31-36.

McLaren, P. (1995). Critical pedagogy and predatory culture. New York: Routledge.

Milner, H. (2003). Reflection, racial competence, and critical pedagogy: How do we prepare pre-service teachers to pose tough questions? Race, Ethicity and Education, 6(2), 193-208.

Milner, H. R. (2010). What does teacher education have to do with teaching? Implications for diversity studies. Journal of Teacher Education, 61(1-2), 118-131.
Nieto, S. (2003). Affirming diversity: The sociopolitical context of multicultural education (4th ed.). New York: Allyn \& Bacon.

Ontario Ministry of Education. (2009). Realizing the promise of diversity: Ontario's equity and inclusive education strategy. Toronto: Queen's Printer for Ontario.

Ryan, J., Pollock, K., \& Antonelli, F. (2009). Leaky pipelines, bottlenecks, and glass ceilings. Canadian Journal of Education, 32(3), 591-617.

Sleeter, C., \& Owuor, J. (2011). Research on the impact of teacher preparation to teach diverse students: The research we have and the research we need. Action in Teacher Education, 33, 524-536.

Tesch, R. (1990). Qualitative research: Analysis types and software tools. New York: The Falmer Press.

Thompson, A. (2003). Tiffany, friend of people of color: White investments in antiracism. Qualitative Studies in Education, 16(1), 7-29. 


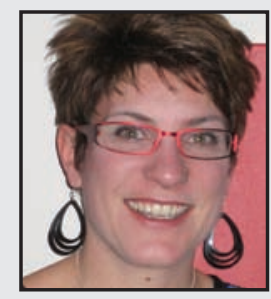

Christine L. Cho, PhD is an Assistant Professor at Nipissing University's Schulich School of Education in Brantford, Ontario currently teaching visual arts education and methods courses. Christine is a practicing visual artist and a former $\mathrm{K}-8$ classroom teacher. Her research in teacher education contributes to current educational conversations on racial, ethnic, and linguistic representation in schools specifically exploring the constructions and understandings of teacher identity, including immigrant teacher aspirations, within the structures of schools. Her work challenges pre-service teachers and educators through critical consciousness-raising to examine their own social location and trouble "the way things are" in elementary schools.

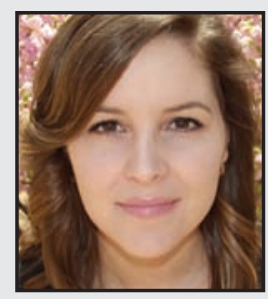

Shannon Tersigni is an elementary school teacher in Guelph, Ontario. She recently completed her Master's of Education thesis at Lakehead University in Thunder Bay, Ontario, where she studied teacher education students' knowledge of social justice and social justice education. Through her continued research in social justice issues in education, Shannon aims to expose inequities within and perpetuated by education systems in Ontario. Her work challenges educators to critically examine their current understandings of social justice and social justice education, including how their own social locations influence such understandings, and ultimately impact the students they teach.

LINK TO:

https://nipissingu.academia.edu/ChristineCho 